\title{
Does Elastography Have a Place in Evaluating Tissue Stiffness in
} Testicular Torsion?

\author{
Kadir Oymen Hancerliogullari (iD) ${ }^{1, *}$ \\ ${ }^{1}$ Department of Pediatric Surgery, Faculty of Medicine, Ministry of Health Giresun University, Obstetric and Pediatrics Training and Research Hospital, Giresun University, \\ Giresun, Turkey \\ "Corresponding author: Department of Pediatric Surgery, Faculty of Medicine, Giresun University, Giresun, Turkey. Email: droymen@hotmail.com \\ Received 2019 November 27; Revised 2020 March 20; Accepted 2020 March 31.
}

\begin{abstract}
Background: One of the most important urologic emergencies is testicular torsion in children. Elastography is as an objective method in diagnosis and treatment of testicular torsion, with grayscale and colored images. Our study presents an original framework, which may guide certain research and practices in this field.

Objectives: The aim of this study was to evaluate the effectiveness of ultrasound (US)-elastography for the diagnostic performance of testicular torsion.

Materials and Methods: In this experimental study, 16 male white New Zealand rabbits of the same weight and age were selected and divided into two groups. In group I, the right testicle was fixed, and in group II, the right testicle underwent $720^{\circ}$ torsion in a counterclockwise direction and fixed. Following 1 and 2 hours of ischemia, measurements of the right and left testicles were performed simultaneously. The left testicle was measured again after 24 hours in order to better observe the changes that right testicular ischemia might have had on the left testicle.

Results: A statistically significant increase was detected in the elastography values of the right testicle at 1, 2, and 24 hours $(\mathrm{P}<0.05)$. Elastography values were significantly increased in the left testicle after 24 hours $(P<0.05)$. The elastographic measurement values of the testicular tissue increased significantly with the increase in the duration of ischemia.

Conclusion: With the width of its imaging window and healthy evaluation opportunity, elastography is a method in determining tissue stiffness of unilateral and contralateral testicular structures. In this study, the efficacy of elastography was evaluated. As a future research, further studies are needed to evaluate the elastography values in epididmo-orchitis and other causes of acute scrotum.
\end{abstract}

Keywords: Testicular Torsion, Elastography, Decision Making

\section{Background}

One of the most important urologic emergencies is testicular torsion in children. Inflammation, trauma, and heavy physical exercise may induce the development of this pathology between the ages of 10 and 20 years, but it is most commonly seen during puberty and the neonatal period. It could also happen idiopathically. The testicle rotates around the sperm canals, and the blood supply to the testes is interrupted. Risk of torsion is greater in children diagnosed with undescended or retractile testicles, but children with descended testicles are also at risk. Unless torsion is detected and treated within the first few hours, the testicles may need to be removed or infertility may occur. While it is a unilateral event, losses and injuries may occur in the contralateral testicle due to ischemia/reperfusion (1). The most common diagnos- tic methods are ultrasonography (USG) and Doppler ultrasonography $(1,2)$. Diagnosis and surgical repair within the first hour are vital to save the organ. Delayed diagnoses of testicular torsion cases have quite an important place in medical malpractice lawsuits $(1,2)$. Orchitis and epididymitis, which present with severe scrotal pain, are also important to consider in the differential diagnosis. The most important symptom of testicular torsion is pain. Severe pain and swelling occur in the testicle. Lack of heat increase in the area is important in differentiating the case from epididymitis or orchitis. While B-mode USG has high diagnostic value in the pathology of the parenchymal tissue, Doppler USG is more important in showing the lack of blood flow $(3,4)$.

The tissue elastography method has been widely used in the diagnosis and differential diagnosis of testicular infarction cases in recent years $(5,6)$. Elastographic ultra- 
sonography method displays the objectively measured tissue stiffness in gray-scale or colored images (7-9). The realtime wave elastography method is used especially for this purpose. It is the gold standard in the evaluation of tissue damage especially in liver necrosis (9). Higher elastography values show tissue stiffness which may contribute to tissue ischemia. Therefore, we hypothesized that higher elastography values may be encountered in testicles due to tissue ischemia after torsion. In this study, an experimental study was conducted to evaluate the value of real-time tissue elastography method in the diagnosis of testicular torsion.

\section{Objectives}

The aim of this study was to evaluate the effectiveness of ultrasound (US)-elastography for the diagnostic performance of testicular torsion.

\section{Materials and Methods}

This experimental study, which was approved by the local Ethics Committee (2014/06), began with 16 male white New Zealand rabbits of the same weight and age group in the Animal Research Laboratory of Giresun University. The rabbits were purchased from Saki Yenilli limited company (Ankara, Turkey), and were killed with a thiopental preparation (Pentothal) $60 \mathrm{mg} / \mathrm{kg}$ body weight administered intravenously at the end of the experiments. The 16 rabbits were divided into two groups of eight rabbits. In group I (control group), the right testicle was fixed and evaluated by the radiology specialist with US-elastography. In group II (experiment group), the right testicle was torsioned $720^{\circ}$ counterclockwise and fixed to form models of torsion with 1, 2 to 24 hours of ischemia. At the end of the 1st, 2nd, and 24th hours, the testicles were evaluated with US-elastography. Simultaneous measurements were done on the left testicles, but the left testicle was measured again after 24 hours in order to better observe the changes that right testicular ischemia might have on the left testicle. The details of the materials and methods are provided in the sub-sections including surgical procedure, radiological assessment, and statistical analysis as follows:

\subsection{The Surgical Procedure}

All animals' abdomens were cleaned and shaved before the procedure. After achieving muscle relaxation by intramuscular (IM) Fentanyl $0.2 \mathrm{mg} / \mathrm{mL}$ + fluanisone 10 $\mathrm{mg} / \mathrm{mL}\left(\right.$ Hipnorm $\left.{ }^{\circledR}\right)+$ diazepam $0.3 \mathrm{~mL}$ induction, the rabbits were laid on their backs, and the abdomen was entered through a median incision under the umbilicus using sterile technique. The testicular structures were fixed with 5/0 polyglactine sutures. IM Hypnorm $(0.1 \mathrm{~mL} / \mathrm{kg})$ was used at 30-minute intervals for the maintenance of anesthesia. In group II, right testicles were torsioned $720^{\circ}$ counterclockwise and fixed as defined (1).

\subsection{Radiological Assessment}

Grayscale US studies and elastography technique were performed in 4-13 MHz bandwidth linear probe with mean $12 \mathrm{MHz}$ broadband (Esaote, MyLab60, Geneva, Italy; Elaxto image) by the same radiologist. The imaging modality displayed a translucent color map above the gray scale. The colors ranged from green (softness) to red (hardness) to demonstrate tissue characterization. After the compression and decompression cycles, we selected region of interest areas from the testis and fatty tissue. The strain ratios were automatically calculated by the software. Strain ratio technique analyzes the elastographic map of the target lesion in relation to the surrounding tissues. The calculation of strain ratio was based on standard qualitative ultrasound (US) elastography data. Two different areas (A and $\mathrm{B}$ ) were selected for quantitative analysis. Area A was the tortoise testis tissue selected as target lesion and area B was selected as reference soft fatty tissue outside of the target area. The strain ratio was calculated as the quotient of $\mathrm{B} / \mathrm{A}$. The increased ratio was based on the hardness of the target tissue.

\subsection{Statistical Analysis}

The data obtained in this study were evaluated with SPSS 20.0 for Windows statistical software (SPSS version 20.0 SPSS, IBM, NY, USA) package program. The results of the statistical analyses are summarized in Tables 1 and 2. A Mann-Whitney U test was used for variables in groups of two, which did not disperse normally while examining the differences between the two groups. Friedman test was used for the examination of differences between the measurement times of variables obtained at different times. $\mathrm{P}$ values less than 0.05 were considered as statistically significant.

\section{Results}

Sample size, mean, standard deviation and P values of elastography values of the right testicle for the experiment group and control group at 1, 2, and 24 hours were calculated using Mann-Whitney U test. There was a statistically significant difference between the groups in terms of elastography values in the right testicle at 1, 2, and 24 hour evaluations $(\mathrm{P}<0.05)$ (Figure 1$)$. 




Figure 1. Mean elastography values of the right testicle over time $\left({ }^{*}, \mathrm{P}<0.05\right)$

Specifically, the right testicle values at the 1st, 2nd, and 24th hour were found to be significantly higher than those at 0 hour $(\mathrm{P}<0.05)$. There was a significant difference between the right testicle values at 0 and 2 hours, 0 and 24 hours, and 1 and 24 hours $(\mathrm{P}<0.05)$. Moreover, the difference between the right testicle values at the 2nd and 24th hours was insignificant $(\mathrm{P}>0.05)$ (Table 1$)$. The comparison of right testicle values at different hours of ischemia in the experiment group are also illustrated in Figure 2.

Sample size, mean, standard deviation and $P$ values of elastography values of the left testicle for the experiment group and control group at 1, 2, and 24 hours were calculated using Mann-Whitney U test. There was no significant difference between the groups in terms of elastography values in the left testicle $(\mathrm{P}>0.05)$ at 1 and 2 hours; nevertheless, a statistically significant increase was detected in the elastography value in the left testicle at 24 hours $(\mathrm{P}<$ 0.05) (Figure 3).

When elastography evaluations of the left testicles at different times of ischemia were evaluated, we found that there was no significant difference between the measurements after 0 and 1,0 , and 2 , and 1 and 2 hours ( $P>0.05)$. However, there was a significant difference between right testicle values at 0 and 24 hours and 1 and 24 hours $(\mathrm{P}<$ 0.05 ) (Table 2). The comparison of left testicle values at different hours of ischemia in the experiment group are also illustrated in Figure 4.

\section{Discussion}

Testicular torsion is one of the most common surgical emergencies in childhood. It was firstly defined by Hunter in 1810 (10); and later in 1840, Delasiauve (11) reported a 15year-old boy who developed testicular torsion due to undescended testicles (12). Evaluation of testicular torsion, which is among the acute scrotal incidents, is very important. Physical examination gives very important diagnos- tic results in children. The age of the patient is of great importance. The pediatric age group, especially the neonatal and prepubertal periods, carries a high risk of testicular torsion. Testicular torsion begins with sudden onset severe pain $(10,11)$. The children usually describe this pain as abdominal or groin pain. Abdominal and groin pains in children should be evaluated carefully. Lack of fever and presence of nausea and vomiting are among the specific symptoms of testicular torsion (12).

The tissue elastography method has been widely used in the diagnosis and differential diagnosis of testicular infarction cases. Elastographic ultrasonography method displays the objectively measured tissue stiffness in grayscale or colored images. The real-time wave elastography method is used especially for this purpose. The diagnosis of acute testicular torsion has become easier with new technology. B-mode USG Doppler, nuclear medicine tests, and the recently developed elastography with tissue Doppler USG are among these methods. Ultrasound elastography is a noninvasive imaging technique that could be used to define stiffness of the tissues. The principle of elastography is to use repeated, slight pressure on the examined organ with the ultrasound transducer. Various techniques that exist within the elastographic measurement methods include quasi-static vibro-acoustography, transient elastography, acoustic radiation force impulse, shear wave elasticity imaging (SWEI), and supersonic elasticity imaging (SSI) (13-15). It has got potential in differentiation between diseased and normal tissue in clinical practices and has got a lot of advantages. It is easy, cheap, safe and readily repeatable $(16,17)$.

In the study conducted by Ramnarine et al. (18), elastography was proven able to quantify carotid plaque elasticity. In studies performed by Lin et al. (19) on 70 male Wistar rats, and Shi et al. (20) on 62 New Zealand rabbits, real-time elastography was proven as an effective method in showing liver fibrosis. Our study supports the aforementioned studies. The elastography values were determined to be statistically significantly higher in the torsioned right testicle $(\mathrm{P}<0.05)$. In their experimental study on 28 New Zealand rabbits, Chen et al. (21) derived that the contralateral testicular flow patterns of the tissue changed 6 and 24 hours following right testicular torsion in the ultrasonographic measurement controls. We found higher values of elastography measurements at torsioned testicles that increased as the duration of ischemia increased. Therefore, we suggest elastography as a diagnostic tool adjunct to other ultrasonographic features of testicular torsion.

Several studies define contralateral testiscular injury after testicular torsion. The histopathological and biochemical changes were evaluated in the contralateral tes- 


\begin{tabular}{|c|c|c|c|c|}
\hline & \multicolumn{4}{|c|}{ Friedman test } \\
\hline & Number & Values & Standard test statistics & $\mathbf{P}$ \\
\hline Right testicle at $0 \mathrm{~h}$ & 8 & $1.69 \pm 0.04$ & & \\
\hline $1 \mathrm{~h}$ & & & -0.290 & 0.728 \\
\hline $2 \mathrm{~h}$ & & & -0.484 & $0.012^{\mathrm{b}}$ \\
\hline $24 \mathrm{~h}$ & & & -3.098 & $<0.001^{\mathrm{b}}$ \\
\hline Right testicle at $1 \mathrm{~h}$ & 8 & $2.94 \pm 0.08$ & & \\
\hline $2 \mathrm{~h}$ & & & -0.194 & 0.728 \\
\hline $24 \mathrm{~h}$ & & & -2.808 & $0.012^{\mathrm{b}}$ \\
\hline Right testicle at $2 \mathrm{~h}$ & 8 & $3.95 \pm 0.13$ & & \\
\hline $24 \mathrm{~h}$ & & & -2.614 & 0.728 \\
\hline Right testicle at $24 \mathrm{~h}$ & 8 & $8.13 \pm 0.79$ & & \\
\hline
\end{tabular}

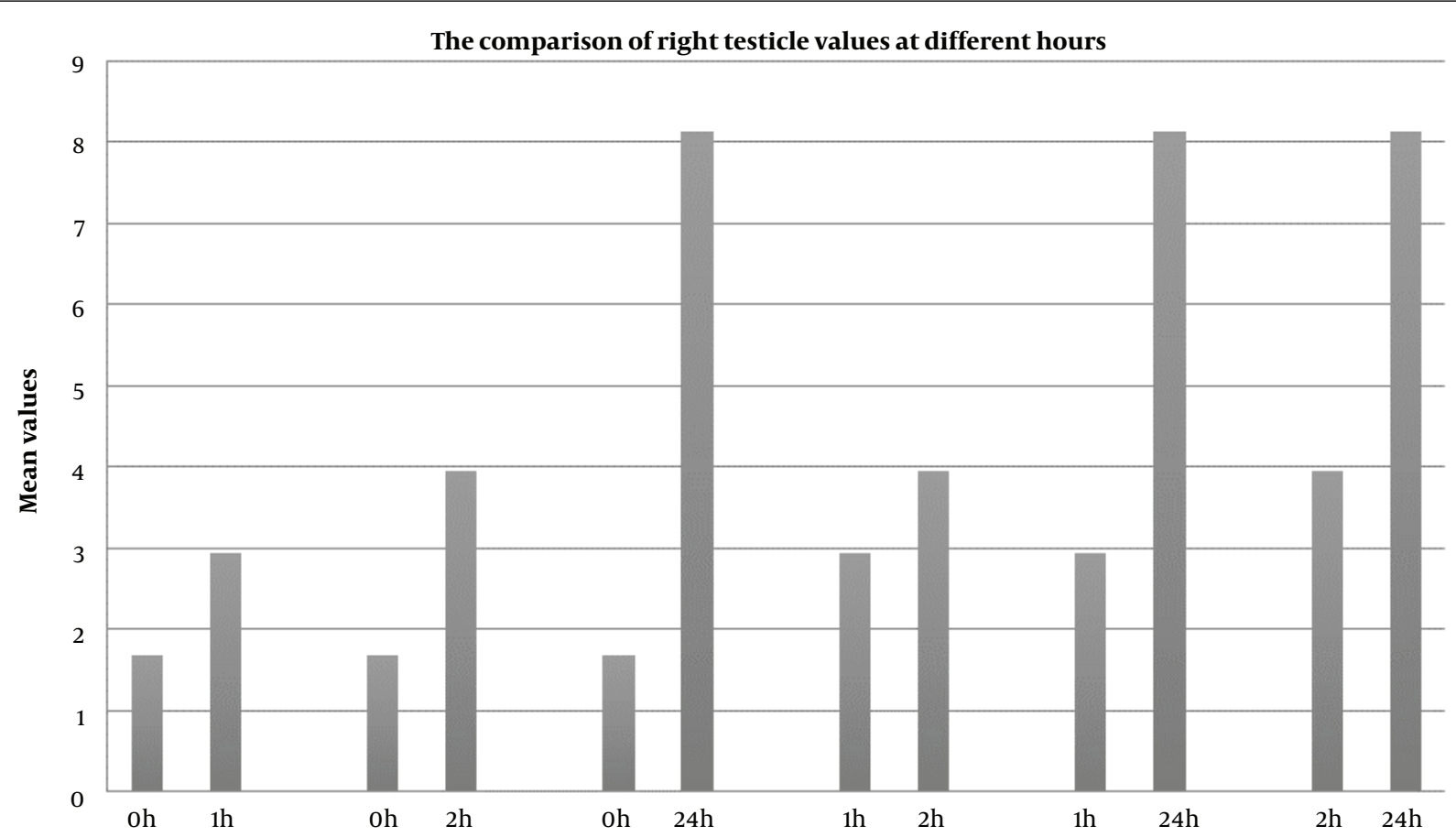

Figure 2. Comparison of mean elastography values of the right testicle (torsioned) at different hours in experiment group

ticle following torsion in their experimental study on 28 adult male Wistar rats, and they detected marked changes in glutathione (GSH), catalase (CAT), malondialdehyde (MDA), and thiobarbituric acid reactive substances (TBARS) levels in the tissue (22).

As it is known, pediatric surgeons and clinicians distinguish testis torsion and epididymorchitis primarily by its clinical status. Testicular torsion and epidimorchitis are not the causes of acute scrotum. Incarcerated inguinal hernia, strangule inguinal hernia, epididymis testicular torsion, testicular trauma, testicular tumors, epididymis testicular torsion, appendix testicular torsion, idiopathic scrotal edema, scrotal hematoma, systemic diseases, Henoch-shonlein purpura are conditions that must 


\begin{tabular}{|c|c|c|c|c|}
\hline & \multicolumn{4}{|c|}{ Friedman test } \\
\hline & Number & Values & Standard test statistic & $\mathbf{P}$ \\
\hline Left testicle at $0 \mathrm{~h}$ & 8 & $1.70 \pm 0.05$ & & \\
\hline $1 \mathrm{~h}$ & & & -1.549 & 0.771 \\
\hline $2 \mathrm{~h}$ & & & -3.098 & 0.628 \\
\hline $24 \mathrm{~h}$ & & & 4.648 & $0.012^{\mathrm{b}}$ \\
\hline Left testicle at $1 \mathrm{~h}$ & 8 & $1.71 \pm 0.06$ & & \\
\hline $2 \mathrm{~h}$ & & & 1.549 & 0.846 \\
\hline $24 \mathrm{~h}$ & & & -3.098 & $0.030^{\mathrm{b}}$ \\
\hline Left testicle at $2 \mathrm{~h}$ & 8 & $1.72 \pm 0.09$ & & \\
\hline $24 \mathrm{~h}$ & & & -1.549 & 0.054 \\
\hline Left testicle at $24 \mathrm{~h}$ & 8 & $1.87 \pm 0.07$ & & \\
\hline
\end{tabular}

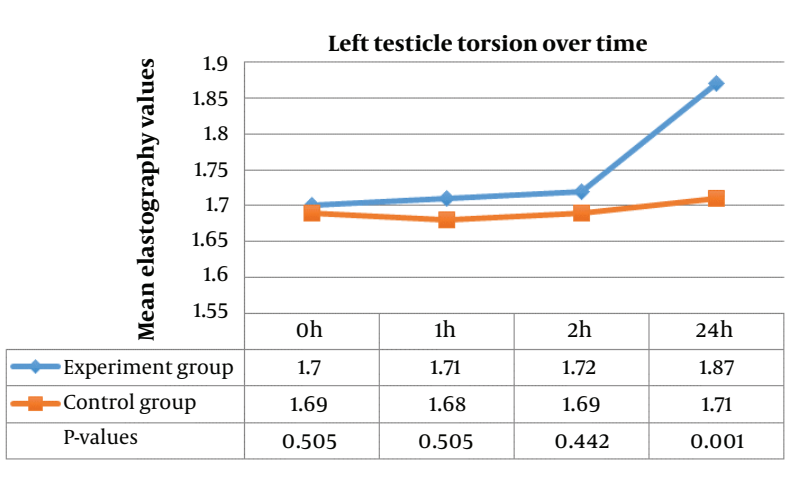

Figure 3. Mean elastography values of the left testicle over time $\left.{ }^{*}, \mathrm{P}<0.05\right)$

also be considered in acute scrotum. While considering all these in the differential diagnosis, clinical findings constitute the most important part. Of course, assisted diagnostic methods are very precious but first of all, whether the patient has pain, how long has the pain continued, the position of the testicle (transverse, or above), presence or absence of the creamaster reflex, Ger's sign (pitting of the skin at the base of the scrotum), Prehn's sign, fever, redness, tenderness, abdominal pain, nausea, and vomiting are the first step of evaluation. We consider physical examination findings and in addition, we look at complete blood count, C-reactive protein (CRP) sedimentation, complete urinalysis. Doppler US, high resolution US, scintigraphy, MRI with dynamic contrast, and near infrared spectroscopy showing the recently used spermatic cord oxygenation could be used as auxiliary tests in diagnosis. Our aim in this study was to investigate the diagnostic performance of elastography, which is a new method in testicular torsion. In order to evaluate the efficiency of elastography in testicular torsion, different new studies are necessary.

Elastographic measurements in this study confirmed the results of previous studies and showed that elastography values could be increased at contralateral testis. Although there was no significant difference between the 1st and 2nd hour elastography values in the left testicle, a statistically significant difference was seen in the 24th hour. Our results suggest that contralateral testicular stiffness could be detected at late term of testicular torsion and it could be detected by elastography in ultrasonographic evaluation.

Goddi et al. (23) researched the role of elastography in the differentiation between malignant and benign testicular masses and found that elastography could better differentiate benign from malignant testicular lesions; however, elastography is a useful technique in assessing small testicular nodules and pseudo-nodules. In the study by Gao et al. (24) on 20 renal transplant patients, they concluded that elastography is useful in assessing the progression of cortical fibrosis in renal transplant allografts. In an experimental in vivo study done by Gao et al. (25), models of acute renal vein occlusion were formed and a significant difference was found in the cortical thickness levels, while they determined that a marked difference was observed in tissue strain and strain relaxation time measurements as the duration of renal vein ligation increased. According to the results of our study, the elastographic measurement values increased significantly with the duration of ischemia, which showed that elastography may aid Doppler USG and color Doppler USG in evaluating the interruption of blood flow in the testicular vessels and the ischemic tis- 


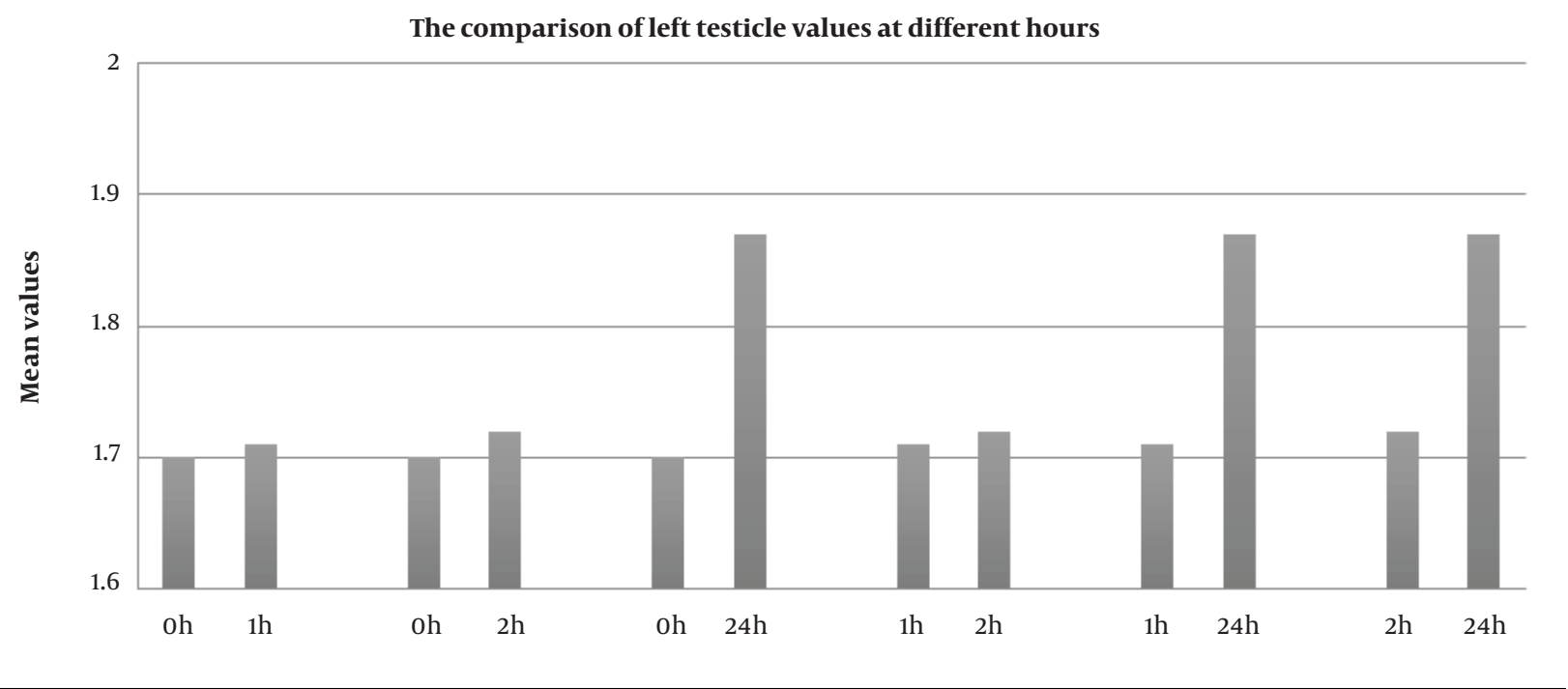

Figure 4. Comparison of mean elastography values of the left testicle (non-torsioned) at different hours in experiment group

sue that occurs with testicular torsion. We found higher values of elastography measurement as early as one hour after ischemia. There was a statistically significant difference between the groups in terms of elastography values in the right testicle at 1st, 2nd, and 24th hour evaluations $(\mathrm{P}<0.05)$. There was no significant difference between the groups in terms of elastography values in the left testicle (P> 0.05) at 1st and 2nd hours; nevertheless, a statistically significant increase was detected in the elastography value in the left testicle at 24th hour $(\mathrm{P}<0.05)$.

Although we did not evaluate the values in other causes of acute scrotum, we suggest that elastography could be used in the early diagnosis of testicular torsion. However, as a future research, further studies are needed to evaluate the elastography values in epididmo-orchitis and in other causes of acute scrotum, to have a firm conclusion about the use of elastography in the differential diagnosis of testicular torsion.

In conclusion, with the width of its imaging window and healthy evaluation opportunity with grayscale and colored images in pediatric testicular torsion cases, elastography is a method in determining the tissue stiffness of unilateral and contralateral testicular structures; and in this study the efficacy of elastography was checked. It was observed that elastography method might contribute to the other diagnostic techniques in the diagnosis of testicular torsion.

\section{Acknowledgments}

The study was presented at the 31st National Congress of Turkish Association of Pediatric Surgeons, in 2015, An- talya. Turkey.

\section{Footnotes}

Authors' Contributions: The author contributed the study design, performed the data collection, and made critical revisions to the paper. Author approved the final version of the manuscript.

Conflict of Interests: The authors declare that they have no competing interest.

Ethical Approval: Ethical approval was issued by the Ethics Committee of the Giresun University Faculty of Health Sciences (decision no.: 2014/06).

Funding/Support: This research did not receive any specific funding or grants from funding agencies in the public, commercial, or non-profit sectors.

Informed Consent: Not applicable.

\section{References}

1. Aslan M, Kucukaslan I, Mulazimoglu S, Soyer T, Senyucel M, Cakmak $\mathrm{M}$, et al. Quantitative software analysis of ultrasonographic textures in experimental testicular torsion. Eur J Pediatr Surg. 2013;23(2):134-9. doi:10.1055/s-0032-1324800. [PubMed: 23093435].

2. Ciftci AO, Senocak ME, Tanyel FC, Buyukpamukcu N. Clinical predictors for differential diagnosis of acute scrotum. Eur J Pediatr Surg. 2004;14(5):333-8. doi: 10.1055/s-2004-821210. [PubMed: 15543483].

3. Sparano A, Acampora C, Scaglione M, Romano L. Using color power Doppler ultrasound imaging to diagnose the acute scrotum. A pictorial essay. Emerg Radiol. 2008;15(5):289-94. doi: 10.1007/s10140-0080710-9. [PubMed: 18351406].

4. Prando D. Torsion of the spermatic cord: the main gray-scale and doppler sonographic signs. Abdom Imaging. 2009;34(5):648-61. doi: 10.1007/s00261-008-9449-8. [PubMed: 18709404]. 
5. Patel KV, Huang DY, Sidhu PS. Metachronous bilateral segmental testicular infarction: Multi-parametric ultrasound imaging with grey-scale ultrasound, Doppler ultrasound, contrast-enhanced ultrasound (CEUS) and real-time tissue elastography (RTE). J Ultrasound. 2014;17(3):233-8. doi: 10.1007/s40477-014-0098-1. [PubMed: 25177399]. [PubMed Central: PMC4142130].

6. Kantarci F, Cebi Olgun D, Mihmanli I. Shear-wave elastography of segmental infarction of the testis. Korean J Radiol. 2012;13(6):820-2. doi: 10.3348/kjr.2012.13.6.820. [PubMed: 23118584]. [PubMed Central: PMC3484306].

7. Lu Y, Wei J, Tang Y, Yuan Y, Huang Y, Zhang Y, et al. Evaluation of fatty liver fibrosis in rabbits using real-time shear wave elastography. Exp Ther Med. 2014;8(2):355-62. doi: 10.3892/etm.2014.1749. [PubMed: 25009583]. [PubMed Central: PMC4079399].

8. Greenleaf JF, Fatemi M, Insana M. Selected methods for imaging elastic properties of biological tissues. Annu Rev Biomed Eng. 2003;5:57-78. doi: 10.1146/annurev.bioeng.5.040202.121623. [PubMed: 12704084].

9. Bercoff J, Tanter M, Fink M. Supersonic shear imaging: A new technique for soft tissue elasticity mapping. IEEE Trans Ultrason Ferroelectr Freq Control. 2004;51(4):396-409. doi: 10.1109/tuffc.2004.1295425. [PubMed: 15139541].

10. Hunter J. A treatise on the venereal disease. London; 1810.

11. Delasiauve LJF. Descente tardive du testicule gauche, prise pour une hernie etranglee. Rev Med Fr Engrang. 1840;1:363-75.

12. Özdemir K, Savas C. Cocuklarda akut skrotal bulgularin degerlendirilmesi. 2009. Available from: http://edergi.sdu.edu.tr/ index.php/sdutfd/article/viewFile/758/867.

13. Cilento BG, Najjar SS, Atala A. Cryptorchidism and testicular torsion. Pediatr Clin North Am. 1993;40(6):1133-49. doi: 10.1016/s00313955(16)38653-9.

14. Kass EJ, Lundak B. Acute scrotum. Pediatr Clin North Am. 1997;44(5):1251-66. doi: 10.1016/s0031-3955(05)70556-3.

15. Zaleska-Dorobisz U, Pawlus A, Szymanska K, Lasecki M, Ziajkiewicz M. Ultrasound elastography-review of techniques and its clinical applications in pediatrics-part 2. Adv Clin Exp Med. 2015;24(4):725-30. doi: 10.17219/acem/34581. [PubMed: 26469119].

16. Bamber J, Cosgrove D, Dietrich CF, Fromageau J, Bojunga J, Calliada F, et al. EFSUMB guidelines and recommendations on the clinical use of ultrasound elastography. Part 1: Basic principles and technology. $U l-$ traschall Med.2013;34(2):169-84. doi:10.1055/s-0033-1335205. [PubMed: 23558397].

17. Sarvazyan A, Hall TJ, Urban MW, Fatemi M, Aglyamov SR, Garra
BS. An overview of elastography - an emerging branch of medical imaging. Curr Med Imaging Rev. 2011;7(4):255-82. doi: 10.2174/157340511798038684. [PubMed: 22308105]. [PubMed Central: PMC3269947].

18. Ramnarine KV, Garrard JW, Kanber B, Nduwayo S, Hartshorne TC, Robinson TG. Shear wave elastography imaging of carotid plaques: feasible, reproducible and of clinical potential. Cardiovasc Ultrasound. 2014;12:49. doi: 10.1186/1476-7120-12-49. [PubMed: 25487290]. [PubMed Central: PMC4293004].

19. Lin SH, Ma JJ, Zhang H, Ding H, Yu Q, Zhu HG, et al. [Real-time elastography for quantitative assessment of liver fibrosis in a rat model]. Zhonghua Gan Zang Bing Za Zhi. 2012;20(5):386-9. Chinese. doi: 10.3760/cma.j.issn.1007-3418.2012.05.017. [PubMed: 22971287].

20. Shi Y, Wang XH, Zhang HH, Zhang HQ, Tu JZ, Wei K, et al. Quantitative analysis of real-time tissue elastography for evaluation of liver fibrosis. Int J Clin Exp Med. 2014;7(4):1014-21. [PubMed: 24955175]. [PubMed Central: PMC4057854].

21. Chen L, Zhan WW, Shen ZJ, Rui WB, Lv C, Chen M, et al. Blood perfusion of the contralateral testis evaluated with contrast-enhanced ultrasound in rabbits with unilateral testicular torsion. Asian J Androl. 2009;11(2):253-60. doi: 10.1038/aja.2008.13. [PubMed: 19151740]. [PubMed Central: PMC3735025].

22. Cvetkovic T, Stankovic J, Najman S, Pavlovic D, Stokanovic D, Vlajkovic $S$, et al. Oxidant and antioxidant status in experimental rat testis after testicular torsion/detorsion. Int J Fertil Steril. 2015;9(1):1218. doi: 10.22074/ijfs.2015.4216. [PubMed: 25918600]. [PubMed Central: PMC4410030].

23. Goddi A, Sacchi A, Magistretti G, Almolla J, Salvadore M. Realtime tissue elastography for testicular lesion assessment. Eur Radiol. 2012;22(4):721-30. doi: 10.1007/s00330-011-2312-2. [PubMed: 22028111]. [PubMed Central: PMC3297754].

24. Gao J, Weitzel W, Rubin JM, Hamilton J, Lee J, Dadhania D, et al. Renal transplant elasticity ultrasound imaging: correlation between normalized strain and renal cortical fibrosis. Ultrasound Med Biol. 2013;39(9):1536-42. doi:10.1016/j.ultrasmedbio.2013.04.007. [PubMed: 23849389].

25. Gao J, He W, Cheng LG, Li XY, Zhang XR, Juluru K, et al. Ultrasound strain elastography in assessment of cortical mechanical behavior in acute renal vein occlusion: in vivo animal model. Clin Imaging. 2015;39(4):613-8. doi: 10.1016/j.clinimag.2014.11.008. [PubMed: 25481219]. 